\title{
Breast Screening in the UK - a National Quality Assured Programme
}

\author{
Ruchi Sinnatamby Peter D. Britton \\ Cambridge Breast Unit, Cambridge University Hospitals NHS Foundation Trust, Addenbrookes Hospital, Cambridge, United Kingdom
}

\section{Key Words}

Breast screening · Mammography · Quality assurance

\section{Summary}

The UK Breast Screening Programme, the first national programme of its kind worldwide, has many strengths not least of which is its stringent programme of quality assurance. This article charts the evolution of the programme over the last 20 years, discusses its performance, the problems it has faced, and how the programme maintains its high quality service.

\section{Introduction}

It is now over 20 years since the UK embarked on a national mammographic screening programme - the first of its kind in the world. Since then, over 19 million women have been screened, and currently 2 million are invited for screening each year, at a cost to taxpayers of approximately 112 million Euros (£75 million) or 55 Euros per woman [1,2]. Despite criticism from detractors [3], it is generally accepted as providing a high quality service and, occasional setbacks notwithstanding, can be seen as a logistical success on a grand scale. It has not been a static programme but one that has evolved in the light of experience and research evidence. The various landmark changes within the programme are set out in the timeline (table 1).

\section{Schlüsselwörter}

Brustkrebsvorsorgeuntersuchung - Mammographie . Qualitätskontrolle

\section{Zusammenfassung}

Das britische nationale Programm für Brustkrebsvorsorge und Früherkennung, welches weltweit einmalig ist, hat viele Stärken - unter anderem ein strenges Qualitätskontrollprogramm. Dieser Artikel beleuchtet die Entwicklung des Programms während der vergangenen 20 Jahre, untersucht seine Leistungsfähigkeit und aufgetretene Probleme und zeigt wie der hohe Qualitätsstandard aufrechterhalten wird.

\section{Background}

The UK National Health Service Breast Screening Programme (NHSBSP) was first implemented in 1988 on the basis of a government commissioned report by Sir Patrick Forrest, Professor of Surgery at Edinburgh University [4]. Evidence for screening benefit was drawn from randomised and case controlled trials of the 1960s and 1970s which demonstrated a significant reduction in breast cancer mortality [5-7]. The model for the NHSBSP was the Swedish Two Counties Trial [8], and a target for breast cancer mortality reduction in the screening age group was set at $25 \%$. Originally, women between 50 and 64 years of age were invited for a single medio-lateral oblique (MLO) view mammogram once every 3 years.

\begin{tabular}{ll}
\hline KARGER & @ 2007 S. Karger GmbH, Freiburg \\
Fax+497614520714 & Accessible online at: \\
$\begin{array}{l}\text { E-mail Information@Karger.de } \\
\text { www.karger.com }\end{array}$ & www.karger.com/brc
\end{tabular}


Table 1. NHSBSP timeline

1986 Forrest report published recommending the introduction of a NHS Breast Screening Programme [4]

1988 NHSBSP begins

1995 Role out of programme in England complete. First Interval cancer data appears $[17,18]$

2001 Informed choice: the programme explains the benefits and limitations of breast screening [24]

2002 Results of the screening interval trial published [23]

2003 Two-view mammography screening at each round is introduced

2004 Screening programme is extended from 50-64 years to 50-70 years

2006 Some digital screening mammography performed [25]

\section{The Current Service}

There are currently 80 NHSBSP units across the UK, most with a target screening population of $60,000-80,000$ women, although this varies according to demographic factors. All women registered with a General Practitioner, between 50 and 70 years, are invited by letter for 3-yearly mammographic screening. Women over the age of 70 do not receive routine invitations but are strongly encouraged to make their own appointments. Two-view (MLO and superior-inferior (SI)) mammography is now performed at each screening round. To maximise ease of access, the majority of women are screened on mobile mammography units moving between centres of population. Exposed films are transported back to the base unit for processing. Less than $3 \%$ of examinations are repeated because of technical inadequacy, necessitating a second attendance. This is a high volume service with 50 or more women being screened each day on mobile units offering appointments every 6 minutes. The national average attendance rate for first invitation to screen is currently $72 \%[2,9]$.

Once checked for quality, films are hung on multi-viewers for reading. The majority of examinations are independently read by 2 screen readers. In most units, at least one of these will be a radiologist, although pilot studies are underway auditing the results of double reading by trained radiographers.

On average, $8.4 \%$ of prevalent and $3.7 \%$ of incident round screens are recalled for further assessment. This evaluation takes place in dedicated breast units and is performed by a mixture of specialist staff including radiologists, radiographers, breast care nurse specialists and surgeons. This multi-disciplinary team of personnel may vary depending upon local staff availability. All radiologists (and radiographers) involved in screen reading should also participate in screening assessment. The assessment process consists of clinical examination, additional mammographic views, ultrasound and, where necessary, needle biopsy. Standards set by national clinical guidelines [10] ensure that this assessment is carried out satisfactorily across the whole of the programme. These standards include the practice of recall by letter rather than telephone, with time between receipt of appointment and attendance being kept as short as practicable to minimise anxiety. Targets include the undertaking of assessment within 15 working days of a screening appointment and the stipulation that at least $95 \%$ of women require no more than 3 separate visits to conclude the diagnostic process.

The aim of assessment is to obtain a definitive diagnosis of all potential screen-detected abnormalities in a timely manner. The process should routinely have only one of two outcomes: return to 3-yearly screening or referral for further treatment for a diagnosis of suspicious or confirmed malignancy. The practice of short-term early re-screen is discouraged, and only $3 \%$ of women undergoing assessment are offered this option [9]. The national guidelines also include detailed protocols for the process of assessment which, whilst not being prescriptive, help maintain best practice across the whole programme. Since the inception of the Screening Programme the widespread use of fine needle aspiration cytology (FNAC) has progressively been replaced by core biopsy [11]. This has resulted in a steadily improving pre-operative cancer diagnosis rate which now stands at $87 \%$.

\section{Strengths of the Programme}

As part of the UK National Health Service, the NHSBSP is free to all participants including women over the age of 70 years who self-refer for screening. Such ideological benefits aside, the UK programme has many strengths. Centralisation of funding ensures equity of resource allocation. An advisory committee oversees the programme and reports to Central Government with recommendations on policy. National co-ordination of organisation facilitates both the setting of standards and the monitoring of quality assurance (QA). Rigorous data collection allows objective measurement of screening performance and outcome. Less easily measurable benefits of national organisation and standardisation of breast screening include the replacement of non-specialist professionals with the nationwide creation of dedicated multi-disciplinary breast teams. This has benefited not just the screening programme but has also transformed symptomatic breast services across the UK.

\section{Maintaining a High Quality Service}

Stringent quality assurance has been a fundamental part of the NHSBSP since its inception and is one of the greatest strengths of the programme. The national QA network is organised on a regional basis with a QA director and QA reference centre for each region [12]. The reference centres collect and collate performance and outcome data from each unit within the region. The QA directors are supported by a regional team which includes a representative co-ordinator from 


\begin{tabular}{|c|c|c|c|c|}
\hline & $\begin{array}{l}\text { Prevalent round - } \\
\text { NHSBSP target } \\
\text { (50-64 years) }\end{array}$ & $\begin{array}{l}\text { Prevalent round - } \\
\text { actual NHSBSP } \\
\text { result } 2004 / 2005\end{array}$ & $\begin{array}{l}\text { Incident round - } \\
\text { NHSBSP target } \\
\text { (50-64 years) }\end{array}$ & $\begin{array}{l}\text { Incident round - } \\
\text { actual NHSBSP } \\
\text { result 2004/2005 }\end{array}$ \\
\hline Acceptance rate, $\%$ & $>70$ & 71.5 & - & 81.5 \\
\hline Recall rate, \% & $<10$ & 8.4 & $<7$ & 3.7 \\
\hline Benign biopsies (per 1,000 women screened) & $<3.6$ & 2.0 & $<2.0$ & 1.0 \\
\hline In situ rate (per 1,000 women screened) & $>0.4$ & 2.0 & $>0.5$ & 1.4 \\
\hline Invasive cancer rate (per 1,000 women screened) & $>2.7$ & 5.2 & $>1.65$ & 5.5 \\
\hline Invasive cancer < $15 \mathrm{~mm}$ (per 1,000 women screened) & $>1.5$ & 2.5 & $>1.7$ & 3.0 \\
\hline Non-operative diagnosis rate for cancers, $\%$ & $>80$ & 80.5 & $>80$ & 86.8 \\
\hline Standardised detection ratio & $>1.0$ & 1.4 & $>1.0$ & 1.4 \\
\hline
\end{tabular}

each of the multidisciplinary professions contributing to the programme (radiology, radiography, pathology, surgery, breast care nursing, administration and medical physics). Regular meetings between these co-ordinators and their professional colleagues help maintain best practice standards and encourage continued improvements. A regular 3-yearly programme of QA inspection visits allows a formal review of the performance, outcomes, organisation and selected case material of each individual unit and ensures that professional competence is maintained [13]. Performance assessed against national targets includes the screening unit's rates for: recall from screening, cancer detection by size, pre-operative diagnosis and benign surgical biopsies amongst many others [14]. Interval cancers, as we will discuss later, are also reviewed. Recommendations resulting from QA visits help strengthen an individual unit's hand in obtaining resources to implement improvements, for example in terms of staffing or equipment shortfalls. Whilst the monitoring and implementation of QA standards occur on a regional basis, these standards are set nationally. National co-ordinating committees comprising the QA directors and regional teams, together with representatives of professional bodies, such as the Royal Colleges, produce guidance on good practice and set national standards and targets for all aspects of the breast screening programme including both staff and equipment. Quality Assurance Guidelines comprising these national standards and targets for performance and outcomes are published by the NHSBSP [1] with more than 60 such guidelines published so far.

Nationally, collected statistics of performance set against these targets are published annually in the NHSBSP statistical bulletin [9]. Table 2 gives some of these most recently published targets and statistics. This data enables assessment of performance of the service as a whole, as well as that of individual units. The problems of comparing the performance of units screening small numbers of variably aged populations was addressed by the development of a performance indicator, the Standardised Detection Ratio (SDR) [15]. This was a modelling device that enabled comparison of a screening unit's cancer detection rate, adjusted for the screening age and UK background incidence, against that detected in a similar aged population in the Swedish Two Counties trial. An SDR of 1 indicated cancer detection rates equivalent to the trial, with the inference that an equivalent mortality reduction could be expected. Figure 1 summarises the performance of the NHSBSP as measured by overall SDR from the start of the programme till 2001. The current (2005/2006) national SDR for prevalent and incident rounds are both 1.4 [9] indicating that NHSBSP units on average are detecting $40 \%$ more cancers than originally detected in the Swedish trial; and data published recently estimates that the programme is now saving approximately 1,400 lives each year in England [16].

Interval cancers are an accepted feature of any screening programme and can be used to measure the performance of a programme. Interval cancer rates will depend upon screening sensitivity and also round length. When the preliminary NHSBSP interval cancer rates were reported [17, 18], they were higher than seen in the Two Counties trial, raising doubts that the trial results could be reproduced. Subsequent data show that interval cancer rates in population screening programmes can be equivalent to those achieved in screening trials [19]. The NHSBSP target for interval cancer rates is 1.2 per 1,000 women screened in the first 24 months after screening and 1.4 per 1,000 women screened between 24 and 36 months after screening [20]. Review and classification of NHSBSP interval cancers is now routine practice and is used not only as a measure of performance, but also as an important part of the continuing education of film readers. The classification of interval cancers according to a 3-tier scheme based upon the imaging findings on original screening mammograms of: normal/benign, uncertain and suspicious, has been published [20] and is well established. In the current climate of open patient information, the proposal that the results of such reviews should be made available to women who have developed interval cancers has sparked sharp debate in screening circles.

\section{Research}

The NHSBSP has, from its very start, been the subject of extensive research. The programme has also specifically com- 
Fig. 1. NHSBSP Standardised Detection Ratio (SDR) for prevalent round screen since the start of screening to-date. The target SDR of 1.0 indicates an invasive cancer detection rate (corrected for background UK incidence) equivalent to that achieved in the Swedish Two Counties trial with the inference that an equivalent mortality reduction should be expected.

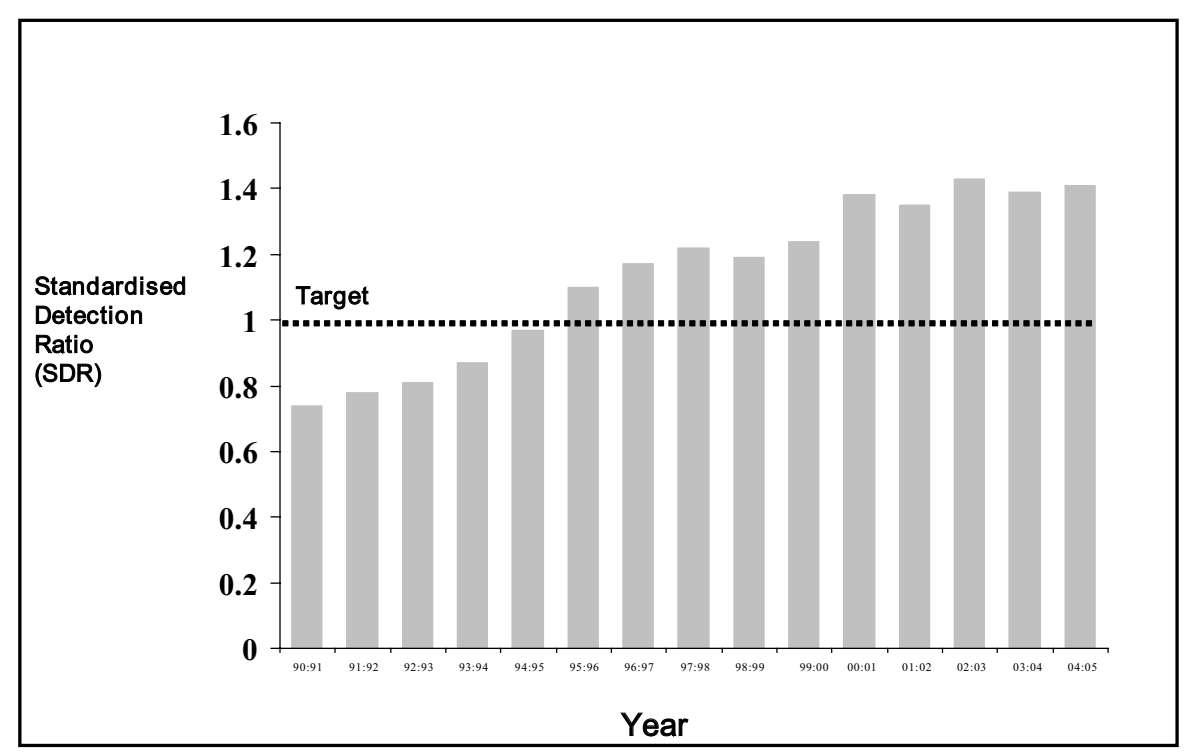

missioned research to address outstanding screening questions raised in the original Forrest report. Evidence from such research has lead to some of the improvements in the programme alluded to earlier, such as the recommendation for double reading [21] and the implementation of two-view mammography, following a study which detected $24 \%$ more breast cancers in women screened with two-view rather than single-view mammography and also reduced the number of patients recalled for assessment [22]. The programme is expected to continue to evolve in the light of ongoing research which includes trials investigating: i) the benefit of screening from age 40: The Age trial (due to conclude soon), ii) the significance and treatment of screen detected DCIS: the Sloane Project, and iii) the role of full field digital mammography in population screening, among many other areas.

\section{Weaknesses and Problems}

Since the start of the NHSBSP, there has been a steady and unrelenting rise in the number of women falling within the screening age band. In 2002, the age range of invitation to screening extended from 50-64 years to 50-70 years. The inclusion of these 2 additional screening rounds represented a $40 \%$ increase in programme workload. Against this background, there has been an ongoing problem of recruiting, training and retaining skilled staff of all specialities but particularly breast radiologists. To enable the programme to expand in the face of such staff shortages, the UK has embraced 'skill mix', whereby radiographers have been encouraged to take on advanced practitioner roles normally performed by radiologists, such as film reading, stereotactic biopsy and ultrasound.
In addition, a new level of radiographer has been developed to address the radiographic shortfall. These assistant practitioners perform similar roles to degree holding radiographers but have a shorter and more focussed training. Whilst these measures have undoubtedly helped maintain the programme, manpower shortages remain one of its biggest problems. These shortages have also been compounded by the diversion of screening funded resources into the symptomatic service which has never received the central resource allocation afforded to the NHSBSP.

The 3-year round length of the NHSBSP is the longest of any national screening programme and has long been a source of debate. In 2001, the results of the NHSBSP frequency trial comparing 1-year with 3-year screening and involving almost 100,000 women was published. Surrogate outcome measures predicted only a modest effect on breast cancer mortality by shortening the screening interval and concluded that measures improving screening quality should be implemented rather than shortening the screening interval [23].

The success of any screening programme is dependant upon the attendance rate of its population. To this end, during the early years of the programme, the potential positive benefits of screening were heavily stressed. The negative aspects of screening, such as false positive recalls, false negative interval cancers and benign surgical biopsies, were largely ignored in original promotional material. With increasing experience and a more vocal and better informed population, the NHSBSP has had to address the issues of informed consent. Women invited for screening are now sent a variety of materials including a leaflet 'Breast screening -The facts' [24] which aims to give a more balanced view of the benefits and potential limitations of the screening programme. 


\section{Conclusions}

The UK NHSBSP was the first national breast screening programme of its kind. It has not been without setbacks, and one of the biggest difficulties in maintaining its ongoing success for the future will be the recruitment, training and retention of staff. Converting from analogue to a digital service is the major technological challenge facing the NHSBSP over the next decade. Although the advantages of film-less screening are self evident and accepted, the technical prob- lems of full field digital mammography on mobile mammography units, the size of data sets and integration with screening computer systems are just some of the problems that will need to be addressed [25]. However, in the 20 years since the recommendation to the UK government to introduce a national breast screening programme, the NHSBSP has developed into an effective high quality service with many strengths, not least of which is its national programme of Quality Assurance.

\section{References}

1 www.cancerscreening.nhs.uk/breastscreen.

2 NHS Breast Screening Programme Annual Review 2006, ISBN 1844630387.

3 Gotzsche PC, Olsen O: Is screening for breast cancer with mammography justifiable? Lancet 2000 355:129-34.

4 Breast Cancer Screening: Report to the Health Ministers of England, Wales, Scotland and Northern Ireland. London, HMSO, 1986, ISBN 011321071X.

5 Shapiro S, Strax P,Venet L: Periodic breast cancer screening in reducing mortality from breast cancer. JAMA 1971:215:1777-85.

6 Collette HJ, Day NE, Rombach JJ, de Waard F: Evaluation of screening for breast cancer in a nonrandomised study (the DOM project) by means of a case-control study. Lancet 1984;1:1224-6.

7 Verbeek AL, Hendriks JH, Holland R, Mravunac M, Sturmans F, Day NE: Reduction of breast cancer mortality through mass screening with modern mammography. First results of the Nijmegen project, 1975-1981. Lancet 1984;1:1222-4.

-8 Tabar L, Fagerberg CJ, Gad A, Baldetorp L, Holmberg LH, Grontoft O, Ljungquist U, Lundstrom B, Manson JC, Eklund G, Day N: Reduction in mortality from breast cancer after mass screening with mammography. Randomised trial from the Breas Cancer Screening Working Group of the Swedish National Board of Health and Welfare. Lancet 1985; 1:829-32.

9 Statistical Bulletin Breast Screening Programme, England 2004-05, ISBN 1-84636-038-2 www.ic. nhs.uk/pubs.
10 Clinical Guidelines for Breast Cancer Screening Assessment NHSBSP Publication No 49 January 2005, ISBN 184463 020X

11 Britton PD, McCann J: Needle biopsy in the NHS Breast Screening Programme 96/97: How much and how accurate. The Breast 1999;8:5-11.

12 Monitoring NHSBSP Standards: A Guide for Quality Assurance Reference Centres, Version 3, Dec 2005.

13 NHSBSP: Guidelines on Quality Assurance Visits. NHSBSP Publication No. 40. Oct 2000, ISBN $187199733 \times$.

14 Consolidated Guidance on Standards for the NHS Breast Screening Programme. NHSBSP Publication No. 60, Version 2, Apr 2005, ISBN 1844630226.

15 Blanks RG, Day NE, SM Moss: Monitoring the performance of breast screening programmes: use of indirect standardisation in evaluating the invasive cancer detection rate. J Med Screen 1996;3 79-81.

16 Screening for Breast Cancer in England: Past and Future. Advisory Committee on Breast Cancer Screening 2006. NHSBSP Publication No. 61, Feb 2006, ISBN 1844630299.

17 Woodman CB, Threlfall AG, Boggis CR, Prior P: Is the three year breast screening interval too long? Occurrence of interval cancers in NHS breast screening programme's north western region. BMJ 1995;310:224-6.
18 Day N, McCann J, Camilleri-Ferrante C, Britton P, Hurst G, Cush S, Duffy S: Monitoring interval cancers in breast screening programmes: the East Anglian experience. Quality Assurance Management Group of the East Anglian Breast Screening Programme. J Med Screen 1995;2:180-5.

19 Tabar L, Vitak B, Chen HH, Yen MF, Duffy SW, Smith RA: Beyond randomized controlled trials: organized mammographic screening substantially reduces breast carcinoma mortality. Cancer 2001; 91:1724-31.

20 Quality Assurance Guidelines for Breast Cancer Screening Radiology. NHSBSP Publication No. 59 , Jan 2005, ISBN 1844630196

21 Blanks RG, Wallis MG, Moss SM: A comparison of cancer detection rates achieved by breast cancer screening programmes by number of readers, for one and two view mammography: results from the UK National Health Service breast screening programme. J Med Screen 1998;5:195-201.

22 Wald NJ, Murphy P, Major P, Parkes C, Townsend J, Frost C: UKCCCR multicentre randomised controlled trial of one and two view mammography in breast cancer screening. BMJ 1995;311:1189-93.

23 The frequency of breast cancer screening: results from the UKCCCR randomised trial. The Breast Screening Frequency Trial Group. Eur J Cancer 2002;38:1458-64.

24 Breast Screening - The facts: www.cancerscreening.nhs.uk/breastscreen/publications.

25 A Cost Comparison of Full Field Digital Mammography (FFDM) with Film-screen Mammography in Breast Cancer Screening NHSBSP Equipment Report 0403 Feb 2004. www.cancerscreening.nhs.uk/ breastscreen/publications. 